\title{
Resposta do capim mombaça sob efeito de fontes e doses de fósforo na adubação de formação
}

\section{Response of grass mombasa under the effect of sources and doses of phosphorus in the fertilization formation}

\author{
Jefferson Santana da Silva Carneiro ${ }^{1, *}$ (D) , Paulo Sérgio Santos Silva 2, (D) , Antonio Carlos Martins dos Santos 2, (D)

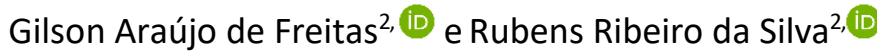 \\ 1 Universidade Federal de Lavras (UFLA). Departamento de Ciência do Solo DCS / UFLA. Caixa Postal 3037, CEP 37200- \\ 000. Lavras-MG, Brasil.
}

2 Universidade Federal do Tocantins, Campus Universitário de Gurupi. Rua Badejos Lt. 07 Ch. 69/72 Zona rural Zona Rural. Caixa-postal: 66, CEP 77402-970. Gurupi-TO, Brasil.

*Autor para correspondência: carneirojss@yahoo.com.br

\section{RESUMO}

OPPEN ACESS

\section{Informações adicionais}

Recebido: 13/08/2016

Aceito: 04/01/2017

Publicado: $15 / 04 / 2017$

Editor:

Vinicius Batista Campos Instituto Federal do Amapá Macapá, AP.

vinicius.campos@ifap.edu.br

Revisão por pares às cegas

Processos de revisão

Prot. 1172016R01 (Brasil)

Prot. 1172016R03 (Brasil)

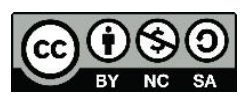

JBFS all rights

Copyright: @ 2017
É característico do cerrado a baixa disponibilidade de fósforo, sendo necessária a sua inclusão de fósforo nas adubações para a obtenção de produtividades satisfatórias das pastagens. O presente trabalho objetivou avaliar o efeito de doses e fontes de fertilizantes fosfatados na adubação de estabelecimento do capim Panicum maximum cv. Mombaça. O experimento foi conduzido na Universidade Federal do Tocantins Campus Gurupi. O delineamento experimental foi em blocos casualizados em esquema fatorial $4 \times 6$. O primeiro fator composto por quatro fertilizante fosfatado: UFT Fértil, Fosfato Natural, Basifós e Superfosfato Simples. O segundo composto por seis doses de fósforo ( $0 ; 35 ; 70 ; 140,210$ e $280 \mathrm{~kg} \mathrm{ha}^{-1}$ de $\mathrm{P}_{2} \mathrm{O}_{5}$ ). A adubação com as diferentes fontes e doses de fósforo influenciaram de forma significativa a produção da forrageira Panicum maximum cv. Mombaça, aumentando a altura do capim, número de perfilhos, massa verde, massa seca da parte aérea e Índice de clorofila Falker. A maior produção do capim Mombaça foi nas doses de 280, 215, 239 e $207 \mathrm{~kg} \mathrm{ha}^{-1}$ de $\mathrm{P}_{2} \mathrm{O}_{5}$ para as fontes UFT Fértil, Fosfato Natural, Basifós e Superfosfato Simples respectivamente. O fertilizante Basifós proporcionou a maior produção da forrageira.

Palavras-chave: Panicum maximum. Forrageira. Cerrado. Manejo da adubação.

\section{ABSTRACT}

It is characteristic of the Cerrado low phosphorus availability, requiring the inclusion of phosphorus in fertilizers to obtain satisfactory productivity of pastures. This study aimed to evaluate the effect of doses and sources of phosphorus fertilizers on grass establishing fertilization Panicum maximum cv. Mombasa. The experiment was conducted at the Federal University of Tocantins - Gurupi Campus. The experimental design was a randomized block in a factorial $4 \times 6$. The first factor consists of four phosphate fertilizer: UFT Fertile, Natural phosphate, Basifós and Simple superphosphate. The second consists of six doses of phosphorus $(0 ; 35 ; 70 ; 140,210$ and $\left.280 \mathrm{~kg} \mathrm{ha}^{-1} \mathrm{P}_{2} \mathrm{O}_{5}\right)$. The fertilization with different sources and phosphorus levels influenced significantly the forage production Panicum maximum cv. Mombasa, increasing grass height, number of tillers, green mass, dry weight of shoot and Falker chlorophyll index. The largest production of Mombasa grass was in doses of 280, 215, 239 and $207 \mathrm{~kg} \mathrm{ha}^{-1} \mathrm{P}_{2} \mathrm{O}_{5}$ for sources UFT Fertile, Natural phosphate, Basifós and Simple superphosphate respectively. The Basifós fertilizer provided the highest yield of forage.

Keywords: Panicum maximum. Forrage. Cerrado. Management of fertilization. 


\section{INTRODUÇÃO}

O Brasil é um dos maiores produtores mundiais de bovinos, com cerca 210 milhões de cabeças (CONAB, 2015). A maior parte do rebanho brasileiro é criada a pasto, em uma área total de 173 milhões de hectares, sendo que cerca de $67 \%$ são de pastagens cultivadas e apenas $3 \%$ desse rebanho são terminados em sistema intensivo (RODRIGUES, 2010; ABIEC, 2016). A maior parte das pastagens cultivadas é representada por gramíneas do gênero Brachiaria. No entanto, as pastagens de capim Brachiaria têm sofrido considerável redução nos últimos anos, e o capim Panicum maximum cv. Mombaça tem sido introduzido em substituição a essas pastagens (DIM et al., 2010). Segundo Vilela (2017) com relação à acidez e à fertilidade do solo o capim Panicum maximum cv. Mombaça é tão exigente quanto às outras cultivares do gênero, no entanto apresenta maior eficiência na utilização do fósforo.

A maior parte das pastagens cultivadas ou nativas encontra-se em algum estádio de degradação que decorre de diversos fatores, entre eles o manejo inadequado das pastagens (ANDRADE et al., 2011). Cerca de 50 a 70\% das áreas de pastagens apresentam algum grau de degradação (DIAS-FILHO, 2014), que se inicia com o manejo animal inadequado, com lotações excessivas ocasionando redução dos níveis de nutrientes e fertilidade do solo, que provoca a perda de vigor e produtividade da pastagem (DUTRA, 2009).

Os solos brasileiros de forma geral apresentam baixa disponibilidade de fósforo, principalmente na região do cerrado, sendo necessária a inclusão de fósforo nas adubações para a obtenção de produtividades satisfatórias das pastagens (SOARES et al., 2001; FARIA et al., 2015). A deficiência de fósforo no solo limita o desenvolvimento radicular, taxa de crescimento inicial, perfilhamento e o estabelecimento das pastagens, limitando sua capacidade produtiva, resultando em baixa produtividade e capacidade de suporte animal (HOFFMANN, 1995; CECATO et al., 2000; OLIVEIRA et al., 2012a; DUARTE et al., 2016).

Sabendo que os solos do cerrado são deficientes em fósforo e da potencial resposta das forrageiras Panicum maximum à adubação fosfatada, o uso eficiente desse nutriente torna-se fundamental para o estabelecimento, sustentabilidade e manutenção da capacidade produtiva dessa forrageira (CECATO et al., 2008; DIAS et al., 2015; VILELA, 2017). Assim o estudo de fontes com diferentes solubilidades e quantidades de fósforo em pastagens cultivadas no cerrado pode definir a quantidade ideal do fertilizante a ser utilizado.

Duarte et al. (2016) citam em seu trabalho que os fertilizantes de alta solubilidade liberam fósforo já nos primeiros meses e os fertilizantes de solubilização lenta liberam o fósforo gradualmente, disponibilizando às plantas por um período mais longo, que são características essenciais quando se visa melhorar a dieta de bovinos em pastejo, aumentando a produtividade e a qualidade nutricional da forrageira. Diante do exposto, o presente trabalho objetivou avaliar o efeito de diferentes doses e fontes de fertilizantes fosfatados utilizados na adubação de estabelecimento do capim Panicum maximum cv. Mombaça.

\section{MATERIAL E MÉTODOS}

A presente pesquisa foi realizada em parceria da Universidade Federal do Tocantins, Cooperativa dos Produtores de Carne e Derivados de Gurupi - COOPERFRIGU e a Empresa Timac Agro Brasil - Indústria e Comércio de Fertilizantes. O experimento foi conduzido na fazenda experimental da Universidade Federal do Tocantins (UFT), Campus Universitário de Gurupi, localizada na Região Sul do Estado do Tocantins, a 280 
m de altitude, nas coordenadas $-11^{\circ} 43^{\prime} 45^{\prime \prime}$ de latitude $\mathrm{Se}-49^{\circ} 04^{\prime} 07^{\prime \prime}$ de longitude W. $\mathrm{O}$ clima regional é do tipo B1WA'a' úmido com moderada deficiência hídrica, segundo a classificação de Köppen (1948). A temperatura, precipitação, umidade relativa do ar e evapotranspiração média nos meses de setembro de 2011 a maio de 2012 estão apresentadas na Figura 1. Foram coletadas amostras de solo da camada $0-20 \mathrm{~cm}$ para análise química e granulométrica (Tabela 1).

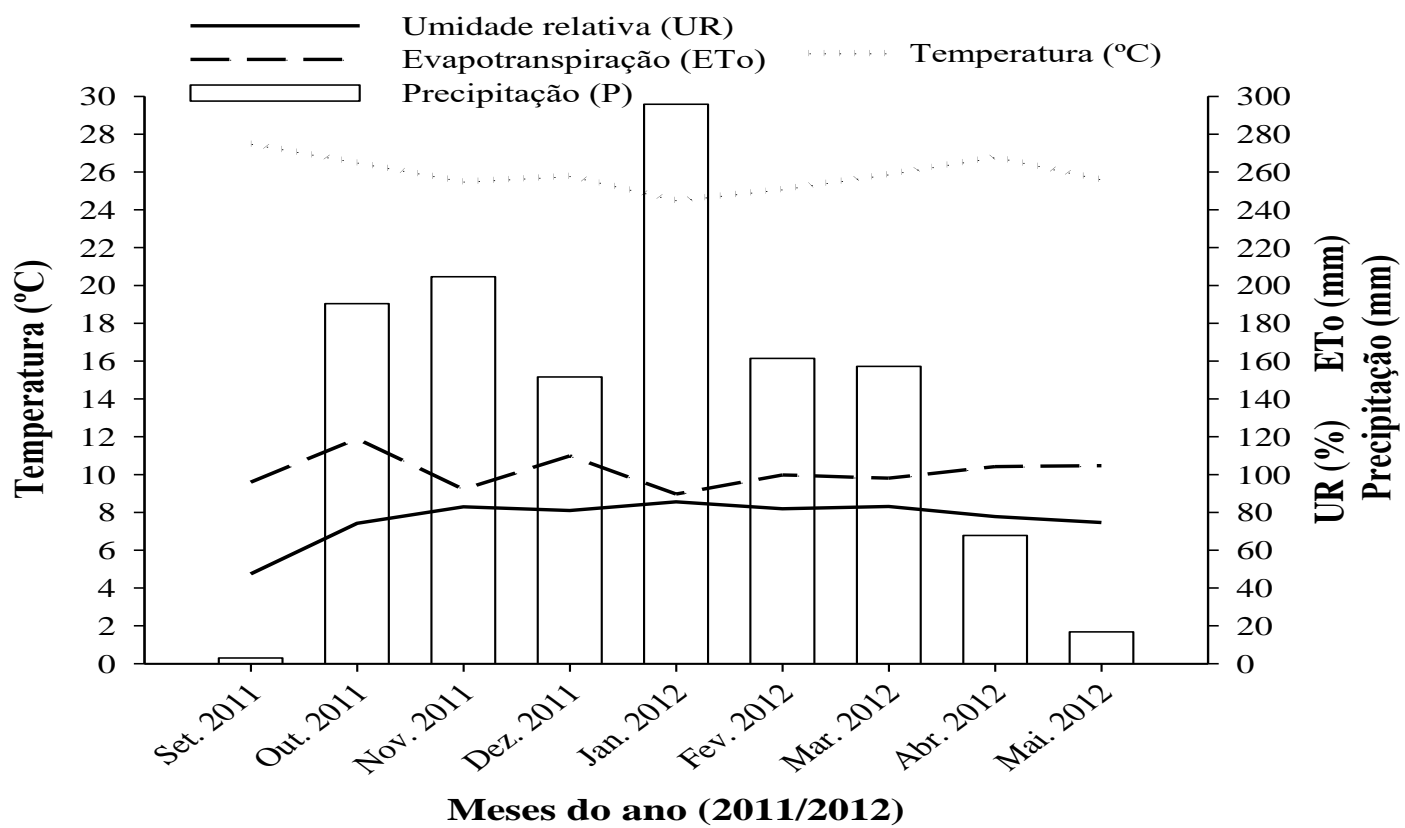

Figura 1. Temperatura, umidade relativa e evapotranspiração média mensal e precipitações observadas no período de dezembro a maio de 2011/2012.

Figure 1. Temperature, relative humidity and average monthly evapotranspiration and precipitations observed from December to May 2011/2012.

Tabela 1. Análise química e física do solo onde foi implantado o experimento de fontes e doses de fertilizantes fosfatados na implantação de pastagem Panicum maximum cv. Mombaça, Gurupi - TO, 2012.

Table 1. Chemical and physical analysis of the soil where the experiment of sources and doses of phosphate fertilizers in the implantation of pasture was implemented Panicum maximum cv. Mombasa, Gurupi - TO, 2012.

\begin{tabular}{|c|c|c|c|c|c|c|c|c|c|c|c|c|c|}
\hline \multirow{2}{*}{ Prof. $(\mathrm{cm})$} & & IVIg & Al & IITA & SB & & & $p$ & M. & pr & reia Sill & Arg & V\% \\
\hline & \multicolumn{6}{|c|}{$-\mathrm{cmol}_{\mathrm{c}} \mathrm{dm}^{-3}$} & \multicolumn{2}{|c|}{$\mathrm{mg} \mathrm{dm^{-3 }}$} & t & $I_{2}$ & 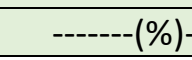 & & \\
\hline 20 & 1,0 & 0,3 & 0,0 & 0,61 & 2,1 & 2,71 & 12 & 1,2 & 17,8 & 4,6 & 7,4 & 22,1 & 77, \\
\hline
\end{tabular}

A adubação de formação foi calculada a partir da análise química do solo, sendo realizada conforme o manual de $5 \underline{a}$ aproximação do estado de Minas Gerais para o médio nível tecnológico (CANTARUTTI et al., 1999).

O experimento foi implantado em um delineamento em blocos casualizados em um esquema fatorial $4 \times 6$. 0 fator um foi composto por quatro fertilizante fosfatado: UFT Fértil (composto de farinha de carne e osso), Fosfato Natural (FN), Superfosfato Simples (SS) e Basifós (Timac Agro Brasil). O segundo fator foi composto por seis doses

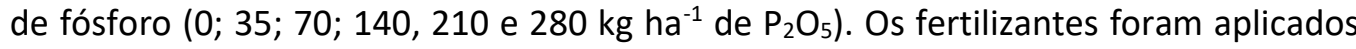
nas seguintes quantidades: $0 ; 0,25 ; 0,5 ; 1,0 ; 1,5 ; 2,0 \mathrm{t} \mathrm{ha}^{-1}$ do fertilizante UFT Fértil; 0 ; 0,$388 ; 0,777 ; 1,555 ; 2,333 ; 3,111 \mathrm{t} \mathrm{ha}^{-1}$ do fertilizante Fosfato Natural (FN); $0 ; 0,194$; 0,$388 ; 0,777 ; 1,166$ e 1,555 t ha $^{-1}$ de Superfosfato Simples (SS) e 0; 0,233; 0,466; 0,933; 
1,40; 1,866 t ha-1 de Basifós. A adubação foi realizada juntamente com o plantio, sendo os mesmos aplicados manualmente a lanço, buscando uma melhor uniformização na distribuição.

A composição química dos fertilizantes é apresentada a seguir: UFT Fértil - 7\% de $\mathrm{N} ; 32 \%$ de $\mathrm{P}_{2} \mathrm{O}_{5}$ total, $0,83 \%$ de $\mathrm{K}_{2} \mathrm{O}, 4,91 \%$ de $\mathrm{Na}, 0,29 \%$ de $\mathrm{Mg}, 12,84$ de $\mathrm{Ca}, 0,08 \%$ de $\mathrm{Zn}, 0,02 \%$ de Cu e 0,32\% de Fe; Fosfato Natural - 24\% de $\mathrm{P}_{2} \mathrm{O}_{5}$ total e $23 \%$ de Ca; Basifós - $3 \%$ de $\mathrm{N}, 26 \%$ de $\mathrm{P}_{2} \mathrm{O}_{5}$ total, $5 \%$ de $\mathrm{K}_{2} \mathrm{O}, 16 \% \mathrm{Ca}, 1 \% \mathrm{~S}, 0,2 \% \mathrm{Zn}, 0,2 \%$ de $\mathrm{Cu}$ e $0,3 \%$ B e Superfosfato Simples - $18 \%$ de $\mathrm{P}_{2} \mathrm{O}_{5}$ total, $18 \%$ de $\mathrm{Ca}$ e $10 \%$ de $\mathrm{S}$.

O experimento foi implantado no mês de outubro e as avaliações realizadas nos meses de novembro (2011) a março (2012). As dimensões das parcelas experimentais foram de $4 \times 5$ metros, largura e comprimento respectivamente e espaçadas entre si por um metro de corredor, totalizando uma área de $20 \mathrm{~m}^{2}$ por parcela. No total o experimento contou com 84 parcelas totalizando $2407 \mathrm{~m}^{2}$ (0,24 ha).

Após o período de 40 dias da implantação do experimento foi realizado um corte de uniformização das parcelas a uma altura de $20 \mathrm{~cm}$ do solo. A avaliação da produção da forrageira foi realizada a cada 21 dias durante os 05 meses de avaliação da pastagem. Para avaliação do efeito das fontes e doses de fósforo sobre as plantas de capim Mombaça foram avaliados os seguintes parâmetros: altura de plantas (AP), perfilhos (PF), massa verde da parte área (MVPA), massa seca da parte aérea (MSPA) e índice de clorofila Falker (ICF).

Para avaliação da altura das plantas foi foram tomadas medidas do solo ao ápice das folhas das plantas (dobras das folhas) em três pontos distintos escolhidos aleatoriamente dentro de cada parcela. Para a determinação da quantidade de perfilho (PF) realizaram-se amostragens da pastagem com o auxílio de quadrado metálico de dimensões conhecidas de $1 \times 1 \mathrm{~m}\left(1 \mathrm{~m}^{2}\right)$, contando-se diretamente o número de perfilhos das plantas dentro do quadrado. Posteriormente foram ceifadas as plantas do interior do quadrado com auxílio de um cutelo para a determinação da massa verde da parte aérea (MVPA), realizando o corte a uma altura de $0,20 \mathrm{~m}$.

A amostra coletada foi pesada em uma balança de precisão, determinando a massa verde produzida pelo capim Panicum maximum cv. Mombaça em uma área de 1 $\mathrm{m}^{2}$. Para a determinação da massa seca (MSPA) o material coletado foi levado para o laboratório onde foram colocadas em uma estufa de secagem de circulação forçada à temperatura entre $65^{\circ} \mathrm{C}$ por 72 horas para a retirada total da água e determinação da massa seca da parte aérea das amostras colhidas da pastagem. Processo esse repetido 05 vezes, a cada 21 dias (período de pousio da pastagem) durante os 5 meses de avaliação da pastagem. Os dados de MVPA e MSPA foram convertidos para $\mathrm{kg} \mathrm{ha}^{-1} \mathrm{a}$ partir dos valores coletados.

Durante a execução do experimento foram realizadas medições da produção fotossintética (clorofila) do capim Mombaça, utilizando um aparelho clorofilômetro portátil. $\mathrm{O}$ aparelho utilizado foi o ClorofiLOG $^{\circ}$ modelo CFL 1030, expressas em unidades chamadas Índice de Clorofila Falker (ICF) (FALKER, 2008). As medidas foram realizadas em plantas escolhidas aleatoriamente, realizando-se a leitura em três folhas de diferentes plantas em três pontos dentro da parcela. As medidas foram realizadas na parte mediana das folhas para uma melhor padronização da coleta, evitando assim discrepâncias nos resultados.

Todos os resultados obtidos nas avaliações realizadas no experimento foram submetidos às análises de variância e regressão com o software Assistat 7.7 beta e os gráficos foram plotados utilizando o software Sigma Plot versão 10.0. Os modelos de regressão foram escolhidos baseados na significância dos coeficientes da equação de regressão e no coeficiente de determinação adotando-se, 1 e $5 \%$ de probabilidade. 


\section{RESULTADOS E DISCUSSÃO}

A adubação com as diferentes fontes e doses de fósforo influenciaram de forma significativa a produção da forrageira Panicum maximum cv. Mombaça. Houve resposta significativa para a altura do capim (AP), número de perfilhos (PF), massa verde (MVPA) e massa seca da parte aérea (MSPA). A altura de plantas (AP) e o número de perfilho (PF) apresentaram respostas quadráticas em função das fontes e doses dos fertilizantes fosfatados (Figura 2).

(A)

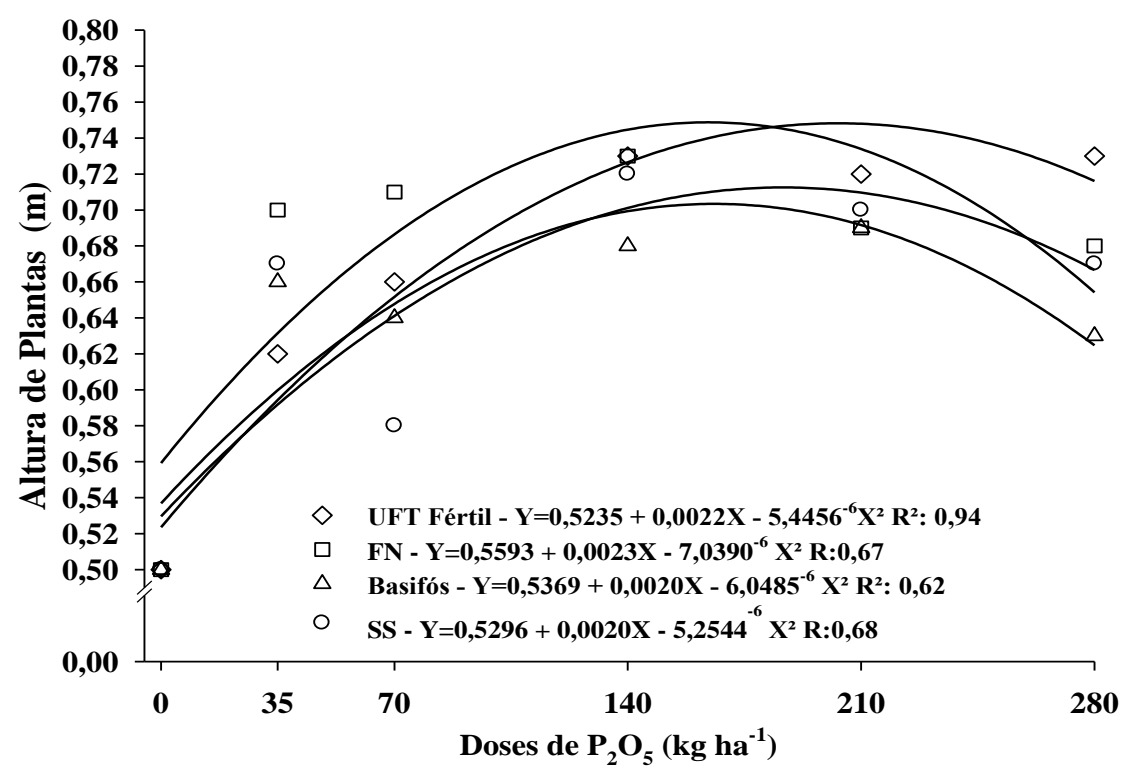

(B)

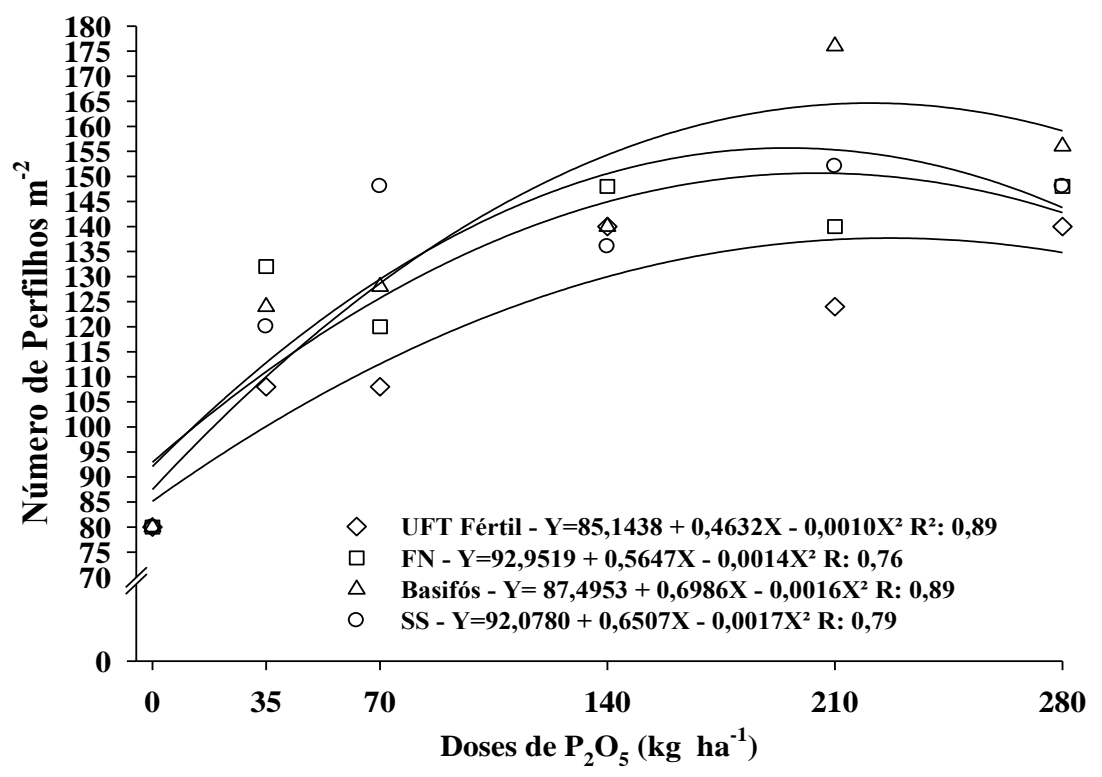

Figura 2. (A) Altura do capim (AP) e (B) número de perfilhos (PF) do Panicum maximum cv. Mombaça em função da aplicação de doses e fontes de fertilizantes fosfatados, Gurupi-TO

(2012).

Figure 2. (A) Grass height (AP) and (B) number of tillers (PF) of Panicum maximum cv. Mombasa according to the application of doses and sources of phosphate fertilizers, Gurupi-TO (2012). 
As maiores alturas estimadas das plantas (AP) (Figura 2A) do capim Mombaça foram de $0,75,0,75,0,70$ e $0,72 \mathrm{~m}$ nas doses de 202, 162, 165 e $190 \mathrm{~kg} \mathrm{ha}^{-1}$ de $\mathrm{P}_{2} \mathrm{O}_{5}$ para as fontes UFT Fértil, FN, Basifós e SS respectivamente. A altura das plantas com uso das fontes de fósforo foi superior cerca de 44, 34, 30 e $36 \%$ em relação a dose $0 \mathrm{~kg} \mathrm{ha}^{-1} \mathrm{de}$ $\mathrm{P}_{2} \mathrm{O}_{5}$ para as fontes UFT Fértil, FN, Basifós e SS respectivamente, sendo estas diferenças muito expressivas, na qual a dose $0 \mathrm{~kg} \mathrm{ha}^{-1}$ de $\mathrm{P}_{2} \mathrm{O}_{5}$ atingiu apenas a altura residual pós pastejo $(50 \mathrm{~cm})$, que seria a altura de saída do gado da pastagem (AGUIAR, 2009).

$O$ acréscimo no crescimento deve-se provavelmente ao melhor desenvolvimento radicular do capim favorecendo uma maior absorção dos nutrientes disponíveis no solo (SANTOS et al., 2002). Os fertilizantes de baixa reatividade podem ser semelhantes aos fertilizantes solúveis quanto à disponibilização de fósforo (CAIONE et al., 2011), o que é comprovado pelas maiores alturas verificadas para os fertilizantes UFT Fértil e o FN.

A superioridade dessas fontes é explicada pelo grande poder residual dos fertilizantes de baixa solubilidade, cuja liberação de fósforo ao solo ocorre de maneira gradual, porém em longo prazo (OLIVEIRA et al., 2012a; DUARTE et al., 2016), assim como a forrageira foi avaliada durante cinco meses simulando pastejo, essa característica de liberação gradual foi de extrema importância para manter a produção constante da forrageira.

O fertilizante que apresentou menor incremento no crescimento do capim Mombaça foi o Basifós, o que é explicado por sua alta solubilidade como comentado por Oliveira et al. (2012a), o qual informa que as fontes mais solúveis disponibilizam grande quantidade de $\mathrm{P}$ nas fases iniciais após o plantio proporcionando assim melhor desenvolvimento inicial das pastagens. No entanto, em longo prazo, esses fertilizantes tendem a reduzir seu efeito sobre a produção da forrageira, uma vez que já tenha sido liberado a maior parte do $\mathrm{P}$ disponível, o que faz com que a produtividade da forrageira seja reduzida diferentemente dos fertilizantes orgânicos pouco solúveis (LIMA et al., 2007). Além de que fertilizantes fosfatados de alta solubilidade quando aplicados em solos intemperizados, grande parte do $\mathrm{P}$ disponível é adsorvido na primeira hora de contato com o solo (OURIVES et al., 2010).

Segundo Patês et al. (2007) há pouca interação entre a presença de fósforo e o crescimento das forrageiras. Segundo esses autores o crescimento está diretamente relacionado à aplicação de fertilizantes nitrogenados ou presença de nitrogênio atmosférico fixado por organismos. No entanto, segundo Werner (1984), Cecato et al. (2007) e Duarte et al. (2016) a ausência da adubação fosfatada ou mesmo a sua ineficiência pode levar a planta a utilizar o fósforo disponível na solução somente para sua manutenção, o que pode ocasionar paralisação da emissão de perfilhos, novas folhas e cessando seu desenvolvimento e produção.

O número de perfilhos (PF) (Figura 2B) das plantas de capim Panicum maximum cv. Mombaça estimadas foram de 139, 150, 164 e 154 perfilhos $\mathrm{m}^{-2}$ nas doses de 232, 202, 218 e $191 \mathrm{~kg} \mathrm{ha}^{-1}$ de $\mathrm{P}_{2} \mathrm{O}_{5}$ para as fontes UFT Fértil, FN, Basifós e SS respectivamente. A quantidade de perfilhos com uso das fontes de fósforo foi superior cerca de 64, 63, 88 e $67 \%$ em relação a dose $0 \mathrm{~kg} \mathrm{ha}^{-1}$ de $\mathrm{P}_{2} \mathrm{O}_{5}$ para as fontes UFT Fértil, $\mathrm{FN}$, Basifós e SS respectivamente.

A maiores quantidades de perfilhos foram verificadas nas fontes mais solúveis (Basifós e SS), resultado semelhante ao observado por Lima et al. (2007), os quais afirma que as fontes de fósforo $(\mathrm{P})$ de maior solubilidade apresentam melhores resultados em relação ao número de perfilhos. Dias et al. (2015) também verificaram maior resposta das fontes mais solúveis, e explicam que isso ocorre em função da intensa atividade meristemática promovida pelo suprimento de fósforo na fase inicial da rebrota da forrageira. Observaram ainda que a adubação com FN propiciou a obtenção de altura e densidade dos perfilhos intermediários aos demais fertilizantes, indicando uma 
disponibilização gradual de $\mathrm{P}$, característica interessante ao cultivo de pastagem, uma vez que a reposição nutricional fosfatada deve ser constante durante o ciclo de cultivo das pastagens.

O comportamento quadrático em função das doses crescentes de $\mathrm{P}_{2} \mathrm{O}_{5}$ com as diferentes ocorre devido a disponibilização excessiva de fósforo em doses elevadas, o que causa crescimento excessivo das plantas, promovendo uma competição entre elas reduzindo assim a quantidade de perfilhos (LIMA et al., 2007). Segundo Corsi \& Nascimento Jr. (1994), citado por Cecato et al. (2008), a densidade populacional de perfilhos aumenta somente até o ponto em que não exista competição entre eles, pois a partir do momento em que passa a ocorrer competição, a população se estabiliza e para cada perfilho que nasce, ocorre morte de outro.

A diferença nas respostas dos fertilizantes está relacionada à sua solubilidade, visto que o Basifós é um fertilizante mais solúvel que o UFT Fértil, disponibilizando assim fósforo mais prontamente para as plantas conforme observado por Oliveira et al. (2012a). Fontes de fósforo de menor solubilidade apresentam maior efeito residual no solo, sendo importante principalmente para a manutenção da fertilidade em longo prazo, porém possui menor eficiência que os fosfatos solúveis em curto prazo (GUEDES et al., 2009). Resultado que contraria os de Benício et al. (2011) onde em seus estudos, avaliando a produção de Panicum maximum cv. Mombaça em função de diferentes fontes de fósforo, verificaram que a fonte de P menos solúvel, dentre as analisadas, proporcionou a maior média para número de perfilhos em relação às demais.

Para Santos et al. (2011) a quantidade de perfilhos e o tamanho das plantas são inversamente proporcionais, em que plantas muito altas apresentam poucos perfilhos e plantas baixas apresentam numerosos perfilhos. Assim, quando comparado à altura das plantas (AP) e à produção de perfilhos (PF) (Figura 2A e B) pode-se observar que as plantas que apresentaram as menores alturas foram as que apresentaram a maior quantidade de perfilhos e vice-versa concordando com Santos et al. (2011).

A massa verde (MVPA) e a massa seca da parte aérea (MSPA) apresentaram respostas quadráticas em função das fontes e doses dos fertilizantes fosfatados, exceto para massa verde com uso da fonte Basifós e massa seca com uso da fonte UFT Fértil, as quais apresentaram resposta linear (Figura 3 ).

A massa verde da parte aérea (MVPA) (Figura 3A) das plantas de capim Panicum maximum cv. Mombaça estimadas foram de 9494, 10326, 13307 e $9738 \mathrm{~kg} \mathrm{ha}^{-1} \mathrm{de}$ forragem nas doses de 265, 198, 280 e $202 \mathrm{~kg} \mathrm{ha}^{-1}$ de $\mathrm{P}_{2} \mathrm{O}_{5}$ para as fontes UFT Fértil, FN, Basifós e SS respectivamente. A massa verde da parte aérea com uso das fontes de fósforo foi superior cerca de 174, 190, 216 e $182 \%$ em relação a dose $0 \mathrm{~kg} \mathrm{ha}^{-1} \mathrm{de}_{2} \mathrm{P}_{2} \mathrm{O}_{5}$ para as fontes UFT Fértil, FN, Basifós e SS respectivamente.

A aplicação dos fertilizantes fosfatados promoveu maior produtividade da parte aérea do capim Panicum maximum cv. Mombaça em função das doses crescentes dos fertilizantes fosfatados. Resultados semelhante ao observado por Maciel et al. (2007), avaliando diferentes fontes de fósforo no desenvolvimento do capim Brachiaria brizantha cv. Marandú. Certamente, isso ocorreu porque o fósforo tem forte influência sobre o perfilhamento que juntamente com as lâminas foliares contribuem para maior produção da parte aérea e consequentemente maior produção de massa verde da parte aérea do capim Mombaça (CECATO et al., 2008).

O fertilizante Basifós foi o que obteve a maior produção de massa verde da parte aérea, atingindo uma produção de $13307 \mathrm{~kg} \mathrm{ha}^{-1}$ na dose de $280 \mathrm{~kg} \mathrm{ha}^{-1}$ de $\mathrm{P}_{2} \mathrm{O}_{5}$. Esse fertilizante apresentou efeito linear na produção da massa verde da parte aérea das plantas de capim Mombaça, mostrando que o mesmo não atingiu seu máximo efeito sobre as plantas podendo apresentar resultados positivos em doses superiores as utilizadas. Por ser um fertilizante mais solúvel que os demais, pode ter ocorrido a 
disponibilização de uma maior quantidade inicial do nutriente à planta promovendo um maior desenvolvimento do capim (LIMA et al., 2007).

(A)
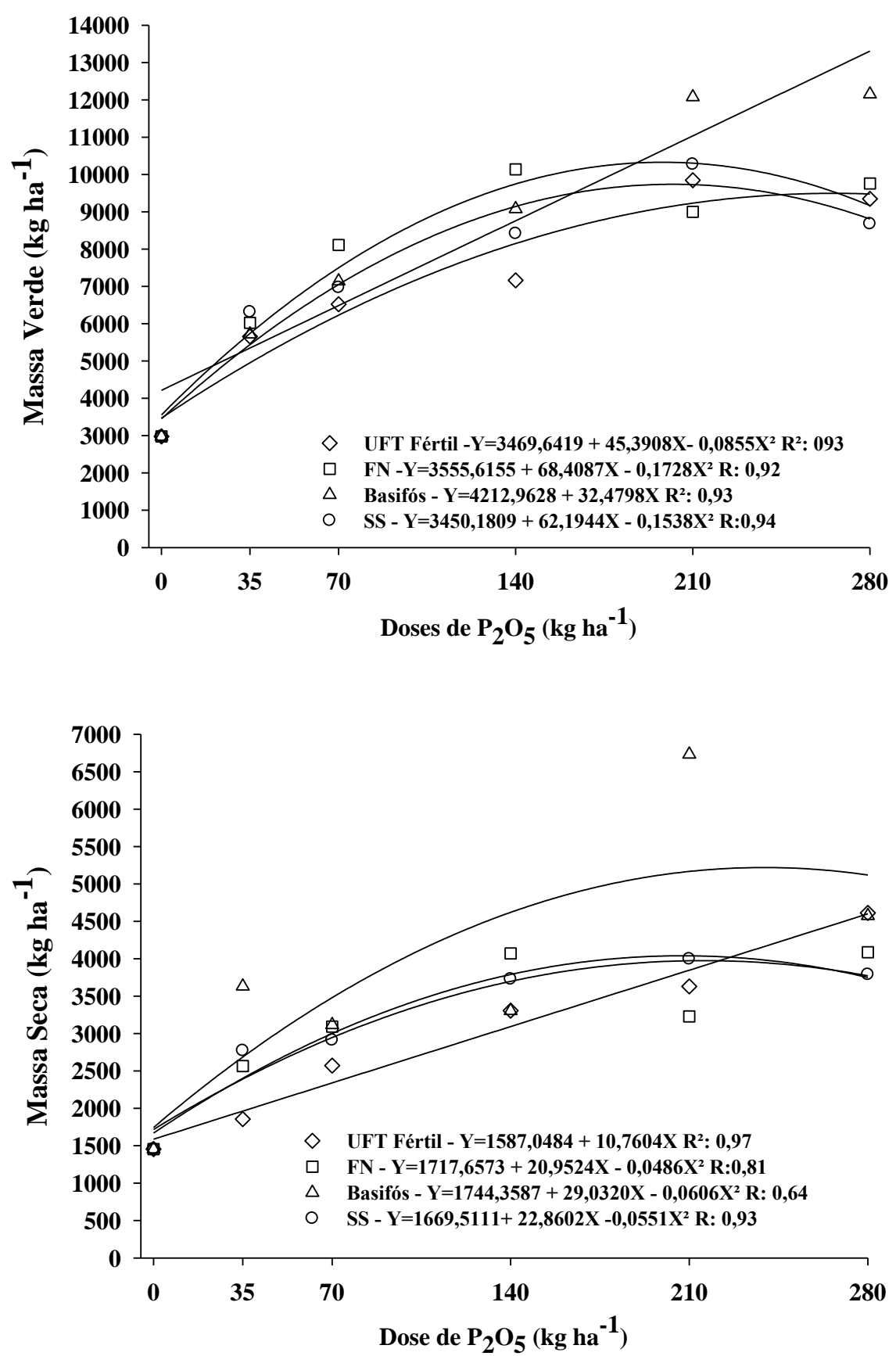

Figura 3. (A) Produção de massa verde (MVPA) e (B) produção de massa seca (MSPA) da parte aérea do capim Panicum maximum cv. Mombaça em função da aplicação de doses e fontes de fertilizantes fosfatados, Gurupi-TO (2012).

Figure 3. (A) Green mass production (MVPA) and (B) dry mass production (MSPA) of aerial part of Panicum maximum cv. Mombasa according to the application of doses and sources of phosphate fertilizers, Gurupi-TO (2012). 
Em contrapartida, o fertilizante UFT Fértil foi o que apresentou as menores médias na produção de massa verde da parte aérea do capim Panicum maximum cv. Mombaça atingindo apenas a produção de $9.494 \mathrm{~kg} \mathrm{ha}^{-1}$, que é uma característica dos fertilizantes orgânicos disponibilizar nutrientes gradualmente para as plantas. Porém com o passar do tempo espera-se que esse fertilizante tenha sua eficiência aumentada.

A massa seca da parte aérea (MSPA) (Figura 3B) das plantas de capim Panicum maximum cv. Mombaça estimadas foram de 4600, 3976, 5536 e $4041 \mathrm{~kg} \mathrm{ha}^{-1}$ de forragem nas doses de 280, 215, 239 e $207 \mathrm{~kg} \mathrm{ha}^{-1}$ de $\mathrm{P}_{2} \mathrm{O}_{5}$ para as fontes UFT Fértil, FN, Basifós e SS respectivamente. A massa seca da parte aérea com uso das fontes de fósforo foi superior cerca de 190, 131, 217 e 142\% em relação à dose $0 \mathrm{~kg}^{\text {ha }}{ }^{-1} \mathrm{de}_{\mathrm{P}_{2} \mathrm{O}_{5}}$ para as fontes UFT Fértil, FN, Basifós e SS respectivamente.

A aplicação dos fertilizantes fosfatados em função das doses proporcionou uma maior produtividade de massa seca da parte aérea do capim Panicum maximum cv. Mombaça, apresentando resultados em sua maioria quadráticos. A adubação fosfatada no estabelecimento de pastagem com capim Panicum maximum cv. Mombaça é de fundamental importância apresentando este melhor produtividade de massa seca da parte aérea, principalmente no Cerrado.

A importância da adubação fosfatada no estabelecimento de pastagens é reforçada por Oliveira et al. (2012a), os quais avaliaram fontes de fósforo no estabelecimento e produtividade de forrageiras e por Mesquita et al. (2004) que avaliaram os teores críticos de fósforo em diferentes solos para as pastagens de Mombaça, Marandu e Andropogon.

O fertilizante Basifós foi o que obteve a maior produção de massa seca da parte aérea do capim Panicum maximum cv. Mombaça, atingindo $5536 \mathrm{~kg} \mathrm{ha}^{-1}$ na dose mais eficiente ( $239 \mathrm{~kg} \mathrm{ha}^{-1}$ de $\mathrm{P}_{2} \mathrm{O}_{5}$ ). O que certamente se deve a maior solubilidade deste fertilizante. Sendo assim, ocorre uma maior disponibilização do nutriente para as plantas promovendo dessa forma, maior produtividade à pastagem. Resultados semelhantes aos de Lima et al. (2007) e Oliveira et al. (2012a) os quais afirmam que fertilizantes mais solúveis apresentam maior produção de massa seca da parte aérea em pastagens.

O fertilizante UFT Fértil proporcionou resposta linear na produção de massa seca das plantas, assim sua maior produção foi na dose de $280 \mathrm{~kg} \mathrm{ha}^{-1}$ de $\mathrm{P}_{2} \mathrm{O}_{5}$. Com base nesse resultado pode-se inferir que esse fertilizante, aparentemente, pode proporcionar respostas positivas na produção de massa das plantas de capim Mombaça em doses superiores as utilizadas. Assim observa-se que os fertilizantes de baixa reatividade são importantes na manutenção da qualidade das pastagens, por apresentarem respostas em longo prazo, como observado por Faria et al. (2015) cuja adubação de formação realizada com fosfato natural mantêm a produtividade da pastagem mesmo após dois anos de implantação.

O uso das fontes e doses crescentes de fósforo influenciaram as taxas fotossintéticas do capim Panicum maximum cv. Mombaça. O Índice de Clorofila Falker (ICF) apresentou resposta quadrática às doses aplicadas independente da fonte utilizada, exceto para o fertilizante UFT Fértil (Figura 4). O ICF apresentou resposta linear quando se utilizou o fertilizante UFT Fértil, mostrando potencial resposta da produção fotossintética em doses superiores a utilizadas no presente estudo.

O índice de clorofila Falker (ICF) das plantas de capim Panicum maximum cv. Mombaça estimadas foram de 37, 38, 40 e 39 nas doses de 280, 205, 262 e $156 \mathrm{~kg} \mathrm{ha}^{-1}$ de $\mathrm{P}_{2} \mathrm{O}_{5}$ para as fontes UFT Fértil, FN, Basifós e SS respectivamente. O ICF com uso das fontes de fósforo foi superior cerca de 9, 12, 14 e $142 \%$ em relação a dose $0 \mathrm{~kg} \mathrm{ha}^{-1} \mathrm{de}$ $\mathrm{P}_{2} \mathrm{O}_{5}$ para as fontes UFT Fértil, FN, Basifós e SS respectivamente. 
O ICFalker do capim Mombaça foi influenciado pela aplicação de fósforo, tendo as parcelas adubadas seu ICF superior à parcela testemunha. $O$ maior ICF Total foi observado para o fertilizante Basifós (40) na dose de $262 \mathrm{~kg} \mathrm{ha}^{-1}$ de $\mathrm{P}_{2} \mathrm{O}_{5}$ e o menor ICF foi observado para o fertilizante UFT Fértil o qual apresentou ICF de 37 na dose $280 \mathrm{~kg}$ $\mathrm{ha}^{-1}$. Observou-se que existe alguma relação entre a produção fotossintética com a produção e desenvolvimento do capim Mombaça, já que os maiores resultados observados da produção e desenvolvimento do capim Panicum maximum cv. Mombaça foram observados nos maiores valores de ICFs.

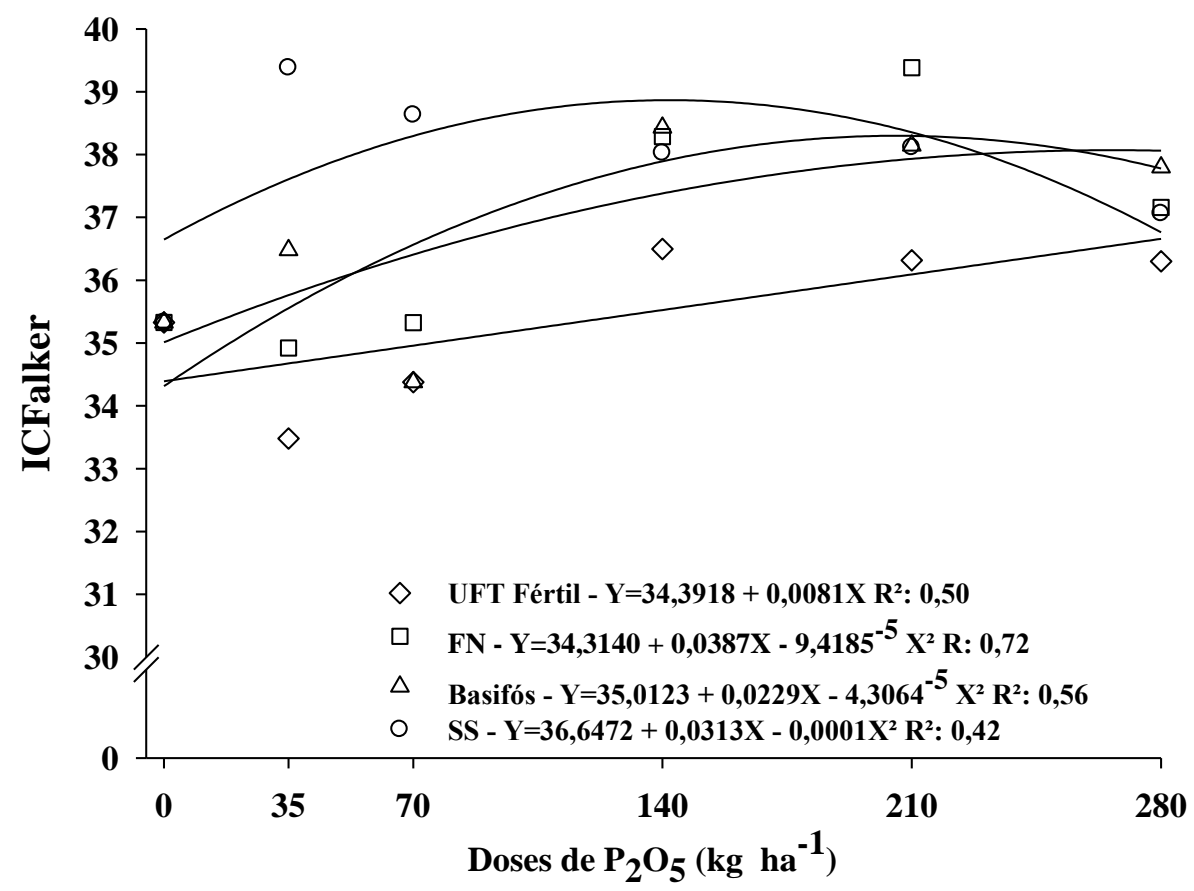

Figura 4. Produção fotossintética (ICF total) do capim Panicum maximum cv. Mombaça em função de doses e fontes de fertilizantes fosfatados, Gurupi-TO (2012).

Figure 4. Photosynthetic production (ICF total) of the Panicum maximum cv. Mombasa as a function of doses and sources of phosphate fertilizers, Gurupi-TO (2012).

Uma possível explicação para a relação positiva entre a adubação com $\mathrm{P}$ e o aumento do índice de clorofila (ICF), pode estar relacionado a um possível aumento absorção de nitrogênio (N), uma vez que o $P$ é principal integrante da ATP, composto que libera energia para o processo ativo de absorção do N (TAIZ \& ZEIGER, 2009). Isso demostra a tamanha importância do fósforo para a produção das forrageiras, uma vez que o $\mathrm{N}$ exerce influência direta sobre a fotossíntese das plantas, garantindo a manutenção da produtividade (SOUZA et al., 2010).

O fósforo é um dos nutrientes que mais limita a produtividade das culturas agrícolas e sua deficiência resulta em decréscimo da fotossíntese das plantas, possivelmente em função do aumento da concentração de amido nas folhas (BROOKS, 1986; FREDEEN et al., 1989; OLIVEIRA et al., 2012b). Segundo Vitor et al. (2009), o maior ICF (Índice de Clorofila Falker) ocorre em plantas com maior disponibilidade de nitrogênio, aumentando a oferta de fotoassimilados e influenciando as características morfogênicas e estruturais da pastagem, como o tamanho das plantas e o número de perfilhos.

Uma dificuldade para utilizar os valores de leitura da produção fotossintética é a variação da concentração de nitrogênio na planta com o estádio de crescimento da planta (ABREU \& MONTEIRO, 1999). Diante disso a padronização dos melhores horários 
para a leitura e estudos de correlação com características das plantas e estados nutricionais favoreceriam uma melhor interpretação do índice de clorofila Falker (ICF) em plantas forrageiras.

De maneira geral a adubação fosfatada aumentou a produção da forrageira Panicum maximum cv. Mombaça. Assim, pouco trabalho relacionado a correção da fertilidade do solo sob pastagens por parte dos produtores tem sido realizado, mesmo com resultados de pesquisa que mostram que essa pratica é de extrema importância para a sustentabilidade e manutenção da produtividade das pastagens brasileira, devendo ser levada aos produtores rurais para implementação da pecuária a pasto.

\section{CONCLUSÕES}

A aplicação de fertilizantes fosfatados proporcionou maior altura de plantas, perfilhamento, produção de massa verde, produção de massa seca e produção fotossintética do capim Panicum maximum cv. Mombaça. A maior produção da forrageira Panicum maximum cv. Mombaça em função das fontes utilizadas foi nas doses de 280, 215, 239 e $207 \mathrm{~kg} \mathrm{ha}^{-1}$ de $\mathrm{P}_{2} \mathrm{O}_{5}$ para as fontes UFT Fértil, FN, Basifós e SS respectivamente.

O fertilizante Basifós proporcionou a maior produção do capim Panicum maximum cv. Mombaça.

\section{CONTIRBUIÇÃO DOS AUTORES}

Elaboração do manuscrito; condução do experimento; análises estatísticas: Autor JSSC; Elaboração do manuscrito; condução do experimento: Autor PSSS; Revisão de literatura; condução do experimento; análises estatísticas: ACMS; e Revisão final do artigo: Autores GAF e RRS.

\section{CONFLITO DE INTERESSE}

Os autores declararam que não há conflito de interesse.

\section{FINANCIAMENTO}

Os autores reportaram que não receberam suporte ou auxílio financeiro para o desenvolvimento da pesquisa.

\section{REFERÊNCIAS}

ABIEC - Associação Brasileira das Indústrias Exportadoras de Carnes. Pecuária Brasileira. Disponível em: <http://www.abiec.com.br/3_pecuaria.asp> Acesso em: 02 de Janeiro de 2017.

ABREU, J.B.R. \& MONTEIRO, F.A. Produção e Nutrição do Capim-Marandu em Função de Adubação Nitrogenada e Estádios de Crescimento. Boletim de Indústria Animal, v.56, n.2, p. 137-146, 1999.

AGUIAR, A.P.A. O Manejo do Pastejo. Curso de pós graduação "lato sensu” em manejo da pastagem. UberabaMG: Faculdades Associadas de Uberaba, 81p. 2009.

ANDRADE, W.R.; SILVA, M.F.; PORTO, E.M.V.; VITOR, C.M.T.; PINTO, F.S. Densidade Populacional de Perfilhos de Cultivares de Brachiaria Brizantha Submetidas a Doses Crescentes de Nitrogênio. 5o Fórum de Ensino, Pesquisa, Extensão e Gestão (FEPEG), Universidade Estadual de Montes Claros, 2011.

BENÍCIO, L.P.F.; OLIVEIRA, V.A.; SILVA, L.L.; ROSANOVA, C.; LIMA, S.O. Produção de Panicum maximum consorciado com sorgo sob diferentes fontes de fósforo. Tecnologia \& Ciência Agropecuária, v.5, n.2, p.5560, 2011.

BROOKS, A. Effects of phosphorus nutrition on ribulose 1,5 - bisphosphate carboxylase activation, photosynthetic quantum yield and amounts of some Calvin cycle metabolites in spinach leaves. Australian Journal of Plant Physiology, v.13, p.221-237, 1986. 
CAIONE, G.; LANGE, A.; BENETT, C.G.S.; FERNANDES, F.M. Fontes de fósforo em variedades de cana-de-açúcar forrageira. Pesquisa Agropecuária Tropical, v. 41, n. 1, p. 66-73, 2011.

CANTARUTTI, R.B.; ALVAREZ V.V.H.; RIBEIRO, A.C. Pastagens. In: RIBEIRO, A.C.; GUIMARÃES, P.T.G.; ALVAREZ V.V.H. (Eds.) Recomendações para uso de corretivos e fertilizantes em Minas Gerais - 5a aproximação. Viçosa, MG: CFSEMG/UFV, 1999. p.332-341.

CECATO, U.; SKROBOT, V.D.; FAKIR, G.M.; JOBIM, C.C.; BRANCO, A.F.; GALBEIRO, S.; JANEIRO, V. Características morfogênicas do capim-mombaça (Panicum maximum Jacq. cv. Mombaça) adubado com fontes de fósforo, sob pastejo. Revista Brasileira de Zootecnia, v.36, n.6, p.1699-1706, 2007.

CECATO, U.; SKROBOT, V.D; FAKIR, G.R.; BRANCO, A.F.; GALBEIRO, S.; GOMES, J.A.N. Perfilhamento e características estruturais do capim Mombaça, adubado com fontes de fósforo, em pastejo. Acta Scientiarum Animal Sciences, v. 30, n. 1, p. 1-7, 2008.

CECATO, U.; YANAKA, F.Y.; BRITO FILHO, M.R.T.; SANTOS, G.T.; CANTO, M.W.; ONORATO, W.M.; PETERNELLI, M. Influência da adubação nitrogenada e fosfatada na produção, na rebrota e no perfilhamento do capimmarandu (Brachiaria brizantha [Hochst] Stapf. cv. Marandu). Acta Scientiarum Animal Sciences, v.22 n.3, p. 817-822, 2000.

CONAB - Companhia Nacional de Abastecimento. Perspectivas para a agropecuária - Safra 2015/2016: Produtos de Verão. Companhia Nacional de Abastecimento - v.3 - Brasília: Conab, p. 1-130, 2015.

CORSI, M. \& NASCIMENTO JÚNIOR, D. Princípios de fisiologia e morfologia de plantas forrageiras aplicados ao manejo das pastagens. In: PEIXOTO, A.M. et al. (Ed.). Pastagens: fundamentos da exploração racional. Piracicaba: Fealq, 1994. p. 15-48.

DIAS, D.G.; PEGORARO, R.F.; ALVES, D.D.; PORTO, E.M.V.; SANTOS NETO, J.A.; ASPIAZÚ, I. Produção do capim Piatã submetido a diferentes fontes de fósforo. Revista Brasileira de Engenharia Agrícola e Ambiental, v.19, n.4, p.330-335, 2015.

DIAS-FILHO, M.B. Diagnóstico das pastagens no Brasil. Empresa Brasileira de Pesquisa Agropecuária, Embrapa Amazônia Oriental - (Documentos 402 / Embrapa Amazônia Oriental). Belém, PA: 2014. 36 p.

DIM, V.P.; CASTRO, J.G.D.; ALEXANDRINO, E.; SANTOS, A.C.; SILVA NETO, S.P. Fertilidade do solo e produtividade de capim Mombaça adubado com resíduos sólidos de frigorífico. Revista Brasileira de Saúde e Produção Animal, v.11, n.2, p. 303-316, 2010.

DUARTE, C.F.D.; PAIVA, L.M.; FERNANDES, H.J.; CASSARO, L.H.; BREURE, M.F.; PROCHERA, D.L.; BISERRA, T.T. Capim-piatã adubado com diferentes fontes de fósforo. Revista Investigação, v.15, n.4, p. 58-63, 2016.

DUTRA, J.E. Recuperação de Pastagem Degradada com Tratamentos Físicos-Mecânicos Associados aos Tratamentos Químicos. Anuário da Produção de Iniciação Científica Discente. Vol. XII, №14 p.371-383 Ano 2009.

FALKER AUTOMAÇÃO AGRÍCOLA Ltda. Manual do medidor eletrônico de teor clorofila (ClorofiLOG/CFL 1030). Porto Alegre, Falker Automação Agrícola. 2008.33p.

FARIA, A.J.G.; FREITAS, G.A.; GEORGETTI, A.C.P.; FERREIRA JÚNIOR, J.M.; SILVA, M.C.A.; SILVA, R.R. da. Efeitos da adubação nitrogenada e potássica na produtividade do capim mombaça cultivados sobre adubação fosfatada. Journal of Bioenergy and Food Science, v.2, n.3, p.98-106, 2015.

FREDEEN, A.L.; RAO, I.M.; TERRY, N. Influence of phosphorus nutrition on growth and carbon partitioning in Glycine max. Plant Physiology, v. 89, p. 225- 230, 1989.

GUEDES, E.M.S.; FERNANDES, A.R.; LIMA, E.V.; GAMA, M.A.P.; SILVA, A.L.P. Fosfato natural de Arad e calagem e o crescimento de Brachiaria brizanta em Latossolo Amarelo sob pastagem degradada na Amazônia. Revista de Ciências Agrárias, v. 52, p. 117-129, 2009. 
HOFFMANN, C.R.; FAQUIN, V.; GUEDES, G.A.A.; EVANGELISTA, A.R. O nitrogênio e o fósforo no crescimento da braquiária e do colonião em amostras de um latossolo da região noroeste do Paraná. Revista Brasileira de Ciência do Solo, v. 19, n. 1, p. 79-86. 1995.

KÖPPEN, W. 1948. Climatologia: con un estudio de los climas de la tierra. Fondo de Cultura Econômica. México. 479pp.

LIMA, S.O.; FIDELIS, R.R.; COSTA, S.J.C. Avaliação de fontes e doses de fósforo no estabelecimento de Brachiaria brizantha cv. Marandu no sul do Tocantins. Pesquisa Agropecuária Tropical, v. 37, n.2, p. 100105, 2007.

MACIEL, G.A.; COSTA, S.E.G.V.A.; FURTINI NETO, A.E.F.; FERREIRA, M.M.; EVANGELISTA, A.R.E. Efeito de diferentes fontes de fósforo na Brachiaria brizantha $\mathrm{cv}$. Marandu cultivada em dois tipos de solos. Ciência Animal Brasileira, v. 8, n. 2, p. 227-233, 2007.

MESQUITA, E.E.; PINTO, J.C.; FURTINI NETO, A.E.; SANTOS, Í.P.A.; TAVARES, V.B. Teores Críticos de Fósforo em Três Solos para o Estabelecimento de Capim-Mombaça, Capim-Marandu e Capim-Andropogon em Vasos. Revista Brasileira de Zootecnia, v. 33, n.2, p. 290-301, 2004.

OLIVEIRA, S.B.; CAIONE, G.; CAMARGO, M.F.; OLIVEIRA, A.N.B.; SANTANA, L. Fontes de Fósforo no Estabelecimento e Produtividade de Forrageiras na Região de Alta Floresta - MT. Global Science and Technology, v. 05, n. 01, p.01-10, 2012a.

OLIVEIRA, T.C.; SILVA, J.; SALGADO, F.H.M.; SOUSA, S.A.; FIDELIS, R.R. Eficiência e resposta à aplicação de fósforo em feijão comum em solos de cerrado. Revista Verde de Agroecologia e Desenvolvimento Sustentável. v.7, n. 1, p. $16-24,2012 b$.

OURIVES, O.E.A.; SOUZA, G.M.; TIRITAN, C.S.; SANTOS, D.H. Fertilizante orgânico como fonte de fósforo no cultivo inicial de Brachiaria brizantha cv. Marandú. Pesquisa Agropecuária Tropical, v.40, n.2, p.126-132, 2010.

PATÊS, N.M.S.; PIRES, A.J.V.; SILVA, C.C.F.; SANTOS, L.C.; CARVALHO, G.G.P.; FREIRE, M.A.L. Características morfogênicas e estruturais do capim-tanzânia submetido a doses de fósforo e nitrogênio. Revista Brasileira de Zootecnia, v.36, n.6, p.1736-1741, 2007.

RODRIGUES, H.V.M. Fósforo e Calagem na Produtividade e Recuperação do Capim Marandú. Dissertação (Mestrado em Produção Vegetal). Universidade Federal do Tocantins, UFT, Gurupi, Tocantins, 2010. 56 f.

SANTOS, H.Q.; FONSECA, D.M.; CANTARUTTI, R.B.; ALVAREZ V., V.H.; NASCIMENTO JÚNIOR, D. Níveis críticos de fósforo no solo e na planta para gramíneas forrageiras tropicais, em diferentes idades. Revista Brasileira de Ciência do Solo, v. 26, n. 1, p. 173-182, 2002.

SANTOS, M.E.R.; FONSECA, D.M.; PIMENTEL, R.M.; SILVA, G.P.; GOMES, V.M.; SILVA, S.P. Número e peso de perfilhos no pasto de capim-braquiária sob lotação contínua. Acta Scientiarum Animal Sciences, v. 33, n. 2, p. 131-136, 2011.

SOARES, W.V.; LOBATO, E.; SOUZA, D.M.G.; VILELA, L. Adubação fosfatada para manutenção de pastagem de Brachiaria decumbens no cerrado. Planaltina-DF; Embrapa Cerrados, setembro 2001. Comunicado técnico № 53.

SOUSA, R.S.; PIRES, A.J.V.; CARVALHO, G.G.P.; SILVA, F.F.; MAGALHÃES, A.F.; VELOSO, C.M. Composição química de capim-tanzânia adubado com nitrogênio e fósforo. Revista Brasileira de Zootecnia, v.39, n.6, p.1200-1205, 2010.

TAIZ, L.; ZEIGER, E. Fisiologia vegetal. 4.ed. Porto Alegre: Artmed, 2009. 819

VILELA, H. Série Gramíneas Tropicais - Gênero Panicum (Panicum maximum- Mombaça - Capim). Disponível em:

http://www.agronomia.com.br/conteudo/artigos/artigos_gramineas_tropicais_panicum_mombaca.htm > Acesso em: 03 Janeiro de 2017. 
VITOR, C.M.T.; FONSECA, D.M.; CÓSER, A.C.; MARTINS, C.E.; JÚNIOR NASCIMENTO, D.; RIBEIRO JÚNIOR, J.I. Produção de matéria seca e valor nutritivo de pastagem de capim-elefante sob irrigação e adubação nitrogenada. Revista Brasileira de Zootecnia, v.38, n.3, p.435-442, 2009.

WERNER, J.C. Adubação de pastagens. Nova Odessa: Instituto de Zootecnia, 1984. 49p. (Boletim Técnico, 18). 